\title{
Platelet inhibitory effects of juices from Pachyrhizus erosus L. root and Psidium guajava L. fruit: a randomized controlled trial in healthy volunteers
}

Thitiporn Thaptimthong, Thitima Kasemsuk, Nathawut Sibmooh and Supeenun Unchern ${ }^{*}$

\begin{abstract}
Background: The purpose of this study is to investigate cardiovascular benefits of juices obtained from two commonly consumed fruits in Thailand, Pachyrhizus erosus, L. (yam bean) and Psidium guajava, L. (guava), by examining their acute cardiovascular effects in healthy volunteers. Possible involvements of the dietary nitrate on their effects were investigated as well.

Method: Thirty healthy volunteers were randomly divided into three groups of 10 subjects per group and each group was allocated to drink $500 \mathrm{ml}$ of freshly prepared yam bean root juice, guava fruit juice, or water. Systemic nitrate and nitrite concentrations, heart rate, systolic and diastolic blood pressure, serum $\mathrm{K}^{+}$concentrations, ex vivo platelet aggregation, and plasma cGMP concentrations were monitored at the baseline and at various time points after the intake of juices or water. Data were compared by repeated measures ANOVA.

Results: Following the ingestion of both yam bean root juice and guava fruit juice, collagen-induced but not ADP-induced platelet aggregation was attenuated. Ingestion of yam bean root juice increased systemic nitrate and nitrite concentrations whereby elevated nitrite concentrations correlated with the extent of inhibiting collagen-induced platelet aggregation. In addition, positive correlation between systemic nitrite and plasma cGMP concentrations and negative correlation between plasma cGMP concentrations and the extent of collagen-induced platelet aggregation were revealed. Nevertheless, yam bean root juice reduced only diastolic blood pressure while guava fruit juice reduced heart rate, systolic and diastolic blood pressure.

Conclusion: The present study has illustrated, for the first time, acute inhibitory effects of yam bean root juice and guava fruit juice on ex vivo collagen-induced platelet aggregation in healthy subjects. Dietary nitrate was shown to underlie the effect of yam bean root juice but not that of guava fruit juice. Following yam bean root juice ingestion, systemic nitrate apparently converts to nitrite and further to NO which may attenuate platelet responses to collagen stimulation. Cardiovascular benefits of juices from yam bean root and guava fruit are noteworthy in term of the cardiovascular health-promoting approach.
\end{abstract}

Trial registration: Randomized controlled trial TCTR20150228001.

Keywords: Yam bean root juice, Guava fruit juice, Systemic nitrate, Systemic nitrite, Plasma cGMP, Antiplatelet effect, Blood pressure lowering effect

\footnotetext{
* Correspondence: supeenun.unc@mahidol.ac.th

Department of Pharmacology, Faculty of Science, Mahidol University, Rama

VI Road, Bangkok 10400, Thailand
} 


\section{Background}

Decreased production of nitric oxide (NO) is evident in essential hypertension and other conditions associated with elevated blood pressure such as diabetes, hypercholesterolemia, and chronic kidney disease [1-6]. Evidence from both human and animal studies showed that nitrate and nitrite derived from diet can serve as a source for NO particularly where it is deficient [7-10], which was firstly demonstrated by Appel and coworkers in 1997 [9]. Nitrate rich diets including green leafy and cruciferous vegetables were reported to have a protective effect on cardiovascular diseases [11, 12].

Following the oral administration of sodium nitrate to healthy volunteers, a significant fall in diastolic and mean arterial blood pressure in association with increasing plasma nitrate was previously demonstrated [13]. Beetroot, a vegetable with high organic nitrate content, reduced blood pressure of healthy volunteers, an effect that correlated with peak increases in plasma nitrite concentrations [14]. Intake of beetroot juice also significantly attenuated ex vivo ADP- and collagen-induced platelet aggregation [14]. In addition, it was demonstrated that the reduction of nitrate to nitrite by oral commensal bacteria was required for blood pressure lowering and platelet inhibitory effects [14].

The formation of blood clot in the circulatory system can lead to disturbances in the blood supply resulting in embolism and stroke. Several fruit juices seem to be able to limit blood clot formation by preventing platelet aggregation in blood vessels $[15,16]$. Fruit juices also play a role in the maintenance of NO levels. This has been shown to occur with many juices [17] including grape [18], pomegranate [19], and citrus juices [20, 21]. These beneficial changes have been noted at various aspects of cardiovascular system including blood pressure [20, 22]. In the prevention of cardiovascular diseases, the consumption of fruits and vegetables is crucial.

Guava (Psidium guajava L.) belongs to the family Myrtaceae and is a traditionally used plant in tropical and subtropical countries because of its food and nutritional value. Every part of guava plant including leaves, root, bark, and fruits has been used for medicinal purposes [23]. The vasodilator and antioxidant actions exerted by guava extracts have been reported [24]. Antihypertensive effect of guava fruit (GF) on spontaneous hypertensive rats was previously demonstrated [25]. Studies using guava leaf extract showed cardio-protective effects against myocardial ischemia-reperfusion injury in the isolated rat heart [26] and cardio-inhibitory action in rats and guinea pig models [27].

Yam bean (Pachyrhizus erosus L.) belongs to the family Leguminosae, subfamily Papilionoidea. In Thailand, yam bean's tuberous root is consumed as fruit or vegetable. There was limited study on pharmacological effects of
YBR. However, the crude fiber extract of YBR was shown to enhance the production of IgM, IgG, IgA, IL-5 and IL-10 by mouse splenocytes [28]. However, there is a lack of information regarding the effects of these plant juices on cardiovascular and platelet functions.

In Thailand, various kinds of fruits are available, however; for public health concern, guava fruit and yam bean root are appropriate for evaluating cardiovascular benefits because they are available throughout the year, not expensive, and thus consumable by all population. The present study was designed to investigate effects of ingesting juices from YBR and GF on heart rate (HR), systolic blood pressure (SBP), diastolic blood pressure (DBP), and platelet aggregation in healthy volunteers. We also examined the possibility that increased plasma nitrate can be achieved through the consumption of these juices, which may consequentially lead to acute reduction of blood pressure and heart rate, and inhibition of platelet aggregation, as a result of bioconversion to nitrite and NO in the body.

\section{Methods \\ Chemicals}

Adenosine diphosphate (ADP) and other chemicals were purchased from Sigma (St Louis, MO). Chrono Par (collagen) was purchased from Chrono-Log Corporation (Havertown, PA). Cyclic GMP ELISA kit was purchased from Assay Designs (Enzo Life Sciences, Inc., NY). Collagen, nitrite preservation solution, sodium nitrite, sodium nitrate, and triiodide solution were prepared freshly prior to use. ADP was dissolved in deionized water as $10 \mathrm{mmole} / \mathrm{L}$ stock solution and kept at $-20^{\circ} \mathrm{C}$.

\section{Fruit materials and preparation of fruit juices}

1. Pachyrhizus erosus L. (Common name: Yam bean; Thai name: Mun-kaew; Cultivar: Small root)

2. Psidium guajava L. (Common name: Guava; Thai name: Fa-rang; Cultivar: Pansetong)

Yam bean root (YBR) and guava fruit (GF) were purchased from Talaad Thai Market, Pathumthani Province, Thailand. Fruits were cleansed and juices were freshly prepared prior to the study by mechanical squeezing the fruit flesh with an electric juicer. Juices were then filtered to remove fibers and pulps. The percentage yield (\% v/w) of juices from the fruit flesh was $47.62 \%$ for YBR and 71.67 \% for GF.

\section{Subjects}

A sample size of 30 subjects completing the study was employed on the basis of estimates from our preliminary data. The sample size provided at least $95 \%$ power to demonstrate a difference between mean of the treatment 
values. The study protocol was approved by the Clinical Research Ethics Committee of Ramathibodi Hospital, Mahidol University (protocol number: ID 03-54-25) that the study was conducted in compliance with the Declaration of Helsinki. Individual subject provided an informed consent after satisfying the inclusion criteria and understanding that he or she could withdraw at any time without a reason. The inclusion criteria were healthy volunteers aged between 20 to 45 years, body mass index (BMI) of $18-27 \mathrm{~kg} / \mathrm{m}^{2}$, and singed informed consent. The exclusion criteria were a history of any serious illnesses, including infectious diseases, cardiovascular and pulmonary diseases, smoking and/or alcoholic drinking, systemic medication (other than oral contraceptive pills), and pregnancy.

\section{Study design}

The study protocol, an open-label, randomized block design, was summarized as a flow chart in Fig. 1. The 30 subjects were randomly allocated into 3 trial groups $(n=10$ per group) to study the ingestion of $500 \mathrm{ml}$ of
YBR juice, GF juice or water. For the allocation of subjects, a drawing lots of subject list was used. Subjects were asked to stop taking certain medications or food supplements (e.g., NSAIDs, fish oil) for 14 days prior to the study, and avoid taking food with high nitrate contents such as processed meat or green leafy vegetables on a day preceding the study. Subjects were fasted overnight or at least $12 \mathrm{~h}$ prior to the studying day and during the morning of that particular day. On the studying day, all subjects were informed that the juice might cause a mild irritation to their stomach. The study took place at Pharmacological Laboratory, Department of Pharmacology, Faculty of Science, Mahidol University, under the supervision and care of physicians.

\section{Blood pressure measurement}

Systolic blood pressure (SBP), diastolic blood pressure (DBP) and heart rate (HR) were measured at the baseline, and monitored every $30 \mathrm{~min}$ for $3 \mathrm{~h}$, and then at $5 \mathrm{~h}$ following juices or water ingestion. All

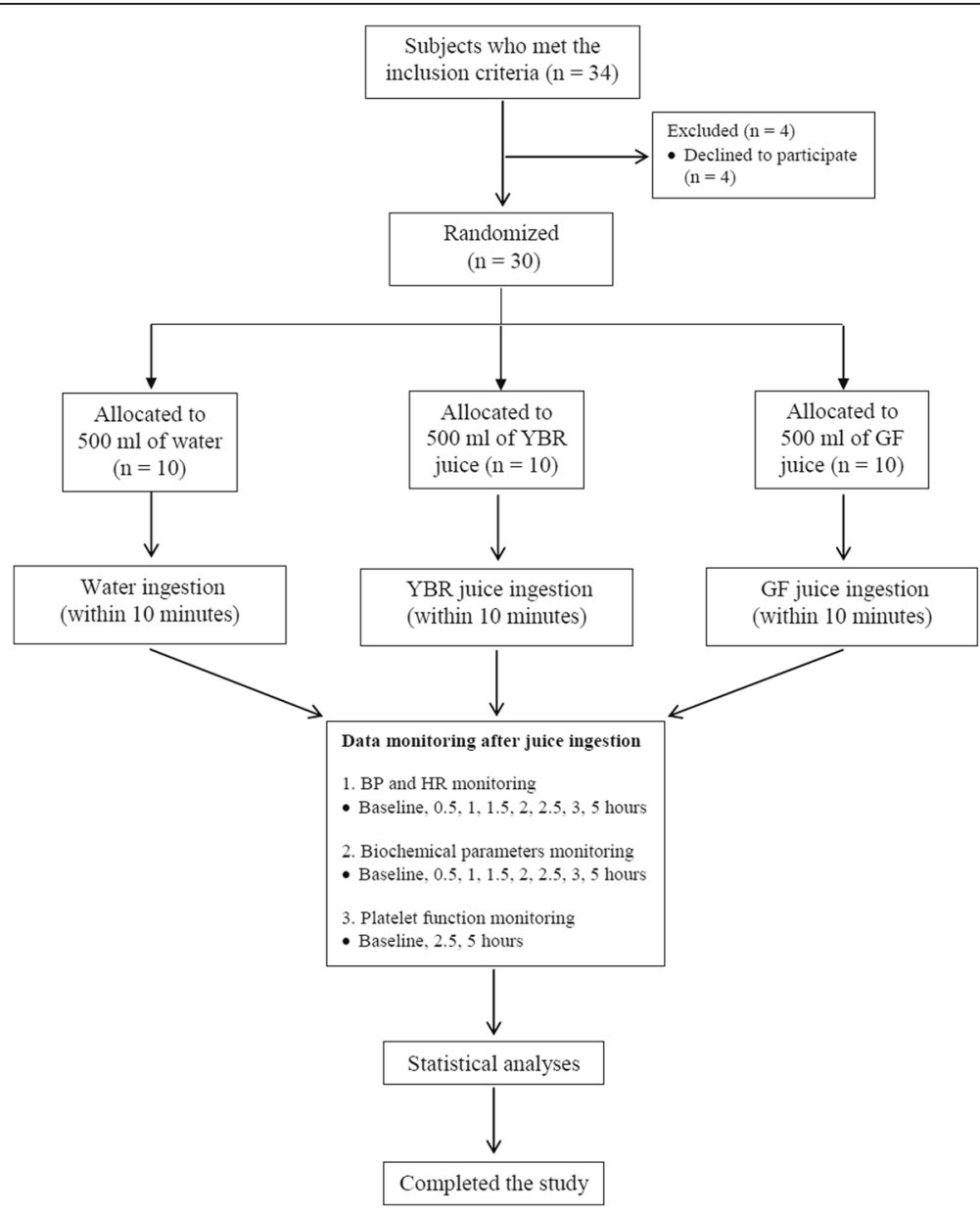

Fig. 1 The flow diagram of progress through phases of the study. Legend: Data monitoring at the baseline was performed prior to the water or juice ingestion. (BP: blood pressure, HR: heart rate, YBR: yam bean root, GF: guava fruit) 
measurements were performed in triplicate with subjects in the seated position using an automatic blood pressure monitor (Omron, model T9P). The mean values of second and third readings were used for data analysis.

\section{Blood sampling}

Ten milliters of blood samples were taken via a $22 \mathrm{G}$ intravenous catheter with extension set at the baseline and at $0.5,1,1.5,2,2.5,3$, and $5 \mathrm{~h}$ after juice or water ingestion. Blood samples were placed into lithium heparinized tubes and citrate tubes for the plasma preparation and assessment of platelet aggregation, respectively.

\section{Determination of nitrate concentrations}

To determine systemic nitrate concentrations, blood samples were placed into heparinized tubes and gently mixed. The heparinized blood were centrifuged at 5,000 $g$ at $4{ }^{\circ} \mathrm{C}$ for $1 \mathrm{~min}$ and then the plasma was separated and stored at $-80{ }^{\circ} \mathrm{C}$ until the nitrate measurement. Nitrate concentrations were determined by a vanadium chloride-based chemiluminescence $\mathrm{NO}$ analyzer (CLD 88 sp, Eco Medics, Switzerland) using sodium nitrate as a standard [29]. Nitrate contents in juices and water were determined by the same method.

\section{Determination of nitrite concentrations}

To determine systemic nitrite concentrations, blood samples were placed into heparinized tubes, gently mixed, and then centrifuged at $5,000 \mathrm{~g}$ for $1 \mathrm{~min}$ at $4{ }^{\circ} \mathrm{C}$ to separate plasma $[30,31]$. All samples were stored at $-80{ }^{\circ} \mathrm{C}$ until the nitrite measurement. Nitrite concentrations were determined by a triiodide-based chemiluminescence NO analyzer (CLD 88 sp, Eco Medics, Switzerland) using sodium nitrate as a standard [30]. Nitrite contents in juices and water were determined by the same method.

\section{Platelet aggregation study}

Blood samples were collected from healthy volunteers and placed in plastic tubes containing $3.8 \%$ sodium citrate in a ratio of 9:1 v/v. Platelet aggregation was assessed in platelet-rich plasma (PRP) which was prepared by centrifugation of citrated blood at $200 \mathrm{~g}$ for $10 \mathrm{~min}$ at $25{ }^{\circ} \mathrm{C}$ and the portion of platelet-rich supernatant was collected. The remaining portion was further centrifuged at $5,000 \mathrm{~g}$ for $10 \mathrm{~min}$ at $25{ }^{\circ} \mathrm{C}$ to obtain platelet-poor plasma (PPP). ADP $(1-4 \mu \mathrm{mole} / \mathrm{L})$ and collagen $(0.5-2 \mu \mathrm{g} / \mathrm{ml})$ were used as agonists for platelet aggregation. The PRP was incubated for $2 \mathrm{~min}$ at $37{ }^{\circ} \mathrm{C}$, calibrated for $100 \%$ light transmission against PPP, stirred for $1 \mathrm{~min}$ at a speed of $1,000 \mathrm{rpm}$ prior to the addition of a platelet agonist (ADP or collagen). Platelet aggregation was monitored by a Chrono-Log aggregometer (Model 540 VS, Chronolog Corp., USA) using the optical aggregation technique as previously described [32, 33].

\section{Determination of plasma cGMP concentrations}

Plasma cGMP levels were determined by using an enzyme immunoassay (Assay Designs' Correlate-EIA ${ }^{\text {tw }}$ cyclic GMP kit) according to the manufacturer's instruction. The heparinized blood samples were immediately centrifuged at $5,000 \mathrm{~g}$ for $1 \mathrm{~min}$ at $4{ }^{\circ} \mathrm{C}$ to separate plasma. Plasma samples were kept below $-20{ }^{\circ} \mathrm{C}$ until the assay.

\section{Determination of serum potassium concentrations}

Serum potassium ion levels were determined using an automated biochemical analyzer (Hitachi, model 912) which based on the ion-selective electrode technique [34].

\section{Statistical analysis}

All data were analyzed using the Graph Pad Prism Software 5.01 and expressed as mean \pm SEM. Data were compared by repeated measures ANOVA test followed by Dunnett's posttest for comparison with baseline values, and followed by Bonferroni posttest for comparison with the control group. The value $P<0.05$ was considered as statistically significant.

\section{Results and discussion \\ Results}

At the baseline, there was no significant difference in general characteristics among subjects in each group (Table 1). Both YBR and GF juices were palatable and well tolerated by all subjects. The mean $( \pm$ SEM) concentrations of nitrate in YBR and GF juices were 5.231 $( \pm 0.173)$ and $0.355( \pm 0.030) \quad \mathrm{mmole} / \mathrm{L}$, respectively. However, nitrite contents of fruit juices and water were below the detection limit $(<50 \mathrm{nmole} / \mathrm{L})$ of the analytical assay.

\section{Systemic nitrate, systemic nitrite, and serum $\mathrm{K}^{+}$ concentrations}

At the baseline, systemic nitrate concentrations in all subject groups were within the normal range, and there was no significant difference among them (Table 1). After YBR juice ingestion, as compared to the control group, there was a rapid and significant $(P<0.05)$ rise of systemic nitrate concentrations, starting within $30 \mathrm{~min}$, peaking at $1.5 \mathrm{~h}$ and remaining at this level up to $5 \mathrm{~h}$ (Fig. 2a). However, there was no similar change after GF juice ingestion (Fig. 2a).

Baseline systemic nitrite concentrations of all subject groups were within the normal range (100-500 nmole/ L) [35] and there was no significant difference among 
Table 1 Demographic characteristics of healthy volunteers at the baseline

\begin{tabular}{|c|c|c|c|c|}
\hline Characteristics & Water (control) & YBR juice & GF juice & Significance value \\
\hline Subject (n) & 10 & 10 & 10 & $P>0.05$ \\
\hline 1. Male & 3 & 3 & 4 & $P>0.05$ \\
\hline 2. Female & 7 & 7 & 6 & $P>0.05$ \\
\hline Age (year) & $27.2 \pm 2.4$ & $26.0 \pm 2.9$ & $25.4 \pm 2.2$ & $P>0.05$ \\
\hline Height (cm) & $163.67 \pm 8.34$ & $164.92 \pm 7.83$ & $166.11 \pm 6.92$ & $P>0.05$ \\
\hline Weight (kg) & $62.04 \pm 12.28$ & $61.17 \pm 9.88$ & $63.11 \pm 11.33$ & $P>0.05$ \\
\hline BMI $\left(\mathrm{kg} / \mathrm{m}^{2}\right)$ & $23.07 \pm 3.75$ & $22.45 \pm 2.30$ & $22.78 \pm 3.37$ & $P>0.05$ \\
\hline Platelet $\times 10^{5}($ per $\mathrm{ml}$ of WB) & $2.19 \pm 0.55$ & $2.21 \pm 0.62$ & $2.50 \pm 0.39$ & $P>0.05$ \\
\hline Plasma nitrate ( $\mu$ mole/L) & $30.16 \pm 4.31$ & $36.43 \pm 5.32$ & $30.35 \pm 1.78$ & $P>0.05$ \\
\hline Plasma nitrite (nmole/L) & $124.04 \pm 9.31$ & $106.87 \pm 18.40$ & $140.12 \pm 2.11$ & $P>0.05$ \\
\hline Plasma cGMP (nmole/L) & $5.37 \pm 0.50$ & $5.613 \pm 2.15$ & $6.97 \pm 2.50$ & $P>0.05$ \\
\hline Serum $\mathrm{K}^{+}$(mmole/L) & $3.98 \pm 0.132$ & $4.09 \pm 0.10$ & $4.01 \pm 0.08$ & $P>0.05$ \\
\hline
\end{tabular}

Data are expressed as mean \pm SEM from subjects in each group. Baseline values were measured at time points prior to YBR juice, GR juice, or water ingestion. Statistical analysis was performed using unpaired Student's $t$-test $v s$. the control

them (Table 1). Following YBR juice ingestion, as compared to the control group, systemic nitrite levels increased significantly $(P<0.05)$ after $1.5 \mathrm{~h}$, peaking at $2.5 \mathrm{~h}$ (4.5 folds), remaining at this level up to $3 \mathrm{~h}$ then returned to near the baseline value by $5 \mathrm{~h}$ (Fig. 2b). There was no change in systemic nitrite concentrations after the ingestion of GF juice (Fig. 2b).

Baseline serum $\mathrm{K}^{+}$concentrations of all subject groups were shown in Table 1 . There was no significant difference among them. In addition, no significant alteration of serum $\mathrm{K}^{+}$levels in healthy volunteers was apparent after the ingestion of YBR juice, GF juice, or water (data not shown).

\section{Effects on ex vivo platelet aggregation}

The mean platelet count of all subject groups was within the normal range $\left(2-4 \times 10^{3}\right.$ per $\mathrm{ml}$ of the whole blood) and there was no significant difference among them (Table 1). At the baseline $(t=0 \quad h)$, ADP dosedependently induced the platelet aggregation with no difference in platelet responses among three subject groups (Fig. 3a, b and c). Both YBR and GF juices did not cause any significant alteration of the platelet aggregation induced by ADP (Fig. 3a, b and c).

Collagen dose-dependently induced the platelet aggregation with no difference in platelet responses among three subject groups at the baseline (Fig. 4a, b and c). Following the ingestion of both YBR and GF juices, the ex vivo collagen-induced platelet aggregation was significantly attenuated $(P<0.05)$ as compared to that of control (Fig. 4a, b, and c).

\section{Effects on plasma cGMP concentrations}

Plasma cGMP concentrations were measured in all subject groups prior to the ingestion of juices or water.
There was no significant difference in baseline plasma cGMP concentrations among three subject groups (Table 1). The YBR juice ingestion caused a slight but significant $(P<0.05)$ increase of plasma cGMP over the baseline value at $2.5 \mathrm{~h}$ and then it declined towards the baseline at $5 \mathrm{~h}$ (Fig. 5). In comparison with the control group, the plasma cGMP concentration at $2.5 \mathrm{~h}$ after the ingestion was significantly higher in YBR group. However, there was no significant change of the plasma cGMP after the ingestion of GF juice (Fig. 5).

\section{Systemic nitrite concentrations vs. plasma cGMP concentrations}

After the YBR juice ingestion, a significant and positive correlation $(P<0.05)$ between the increase of systemic nitrite concentrations and the increase of plasma cGMP concentrations was evident (Fig. 6). However, no correlation between these two variables was found after the ingestion of GF juice (data not shown).

\section{Plasma cGMP concentrations vs. collagen-induced platelet aggregation}

Correlations between systemic nitrate, systemic nitrite, or plasma cGMP concentrations $v s$. the magnitude of ex vivo collagen-induced platelet aggregation were examined. Results showed a significant and negative correlation $(P<0.05)$ between plasma cGMP concentrations and the maximum extent of platelet aggregation induced by varying concentrations of collagen - $0.5 \mu \mathrm{g} / \mathrm{ml}$ (Fig. 7a), $1 \mu \mathrm{g} / \mathrm{ml}$ (Fig. 7b) and $2 \mu \mathrm{g} / \mathrm{ml}$ (Fig. 7c), in YBR juice group. No correlation between these two variables was found in GF juice group (data not shown). 


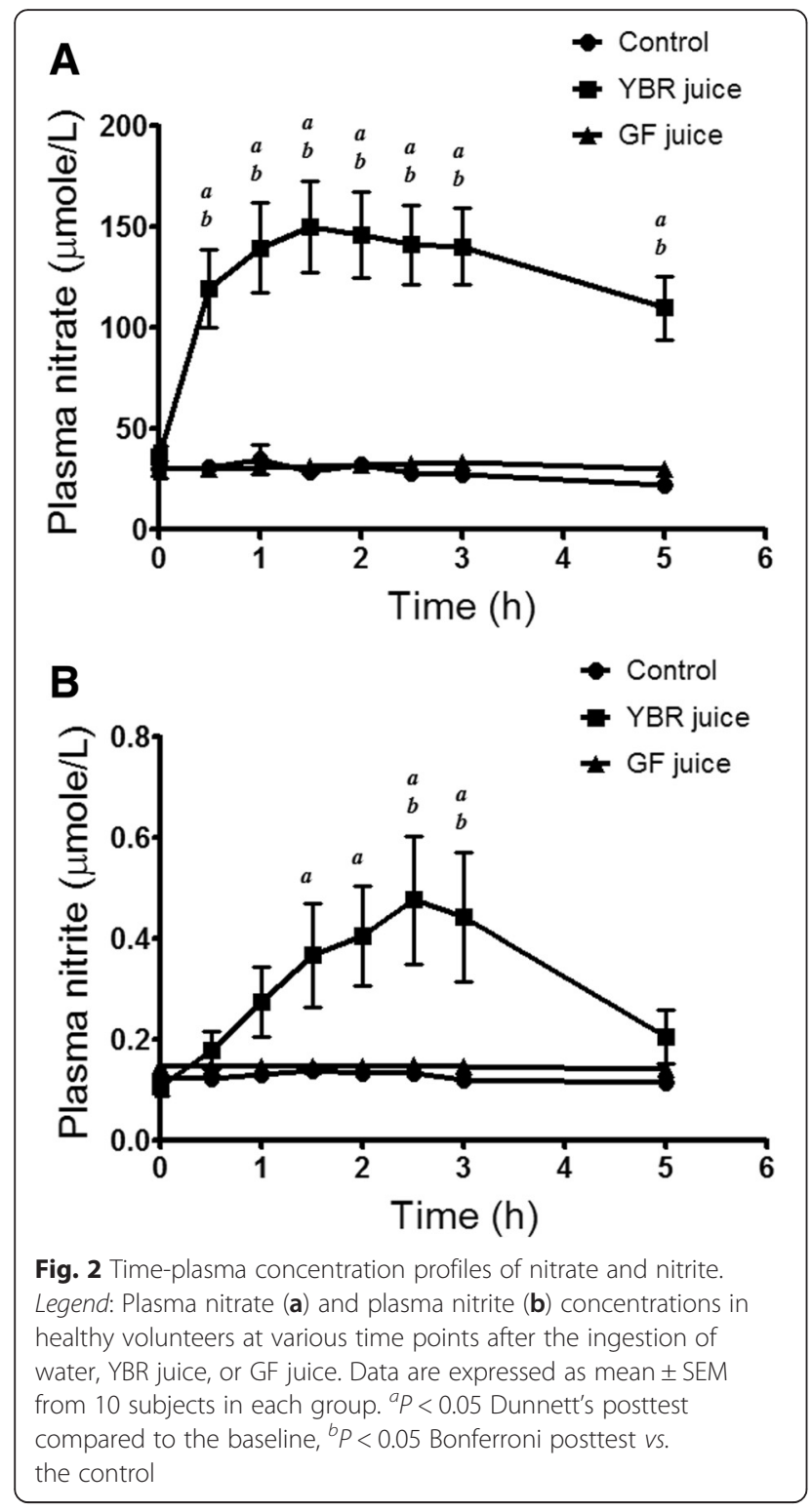

\section{Effects on SBP, DBP and HR}

Effects of YBR and GF juice consumption on SBP, DBP and $\mathrm{HR}$ were observed in healthy volunteers. At the baseline, there was no difference in means $( \pm$ SEM) of SBP, DBP and HR among healthy subjects in all groups (Table 2). Comparing with the water control, a significant reduction $(P<0.05)$ of DBP was apparent only at $0.5 \mathrm{~h}$ after YBR juice intake but not at other time points (Fig. 8c). YBR juice ingestion caused no change in SBP (Fig. 8a) or HR (Fig. 8e) as compared to baseline values. On the contrary, the ingestion of GF juice significantly $(P<0.05)$ reduced SBP (Fig. 8b), DBP (Fig. 8d) and HR (Fig. 8f) at many time points as compared to baseline values. However, only SBP reduction at $5 \mathrm{~h}$ after GF juice intake was significantly $(P<0.05)$ different from that of control (Fig. 8b).

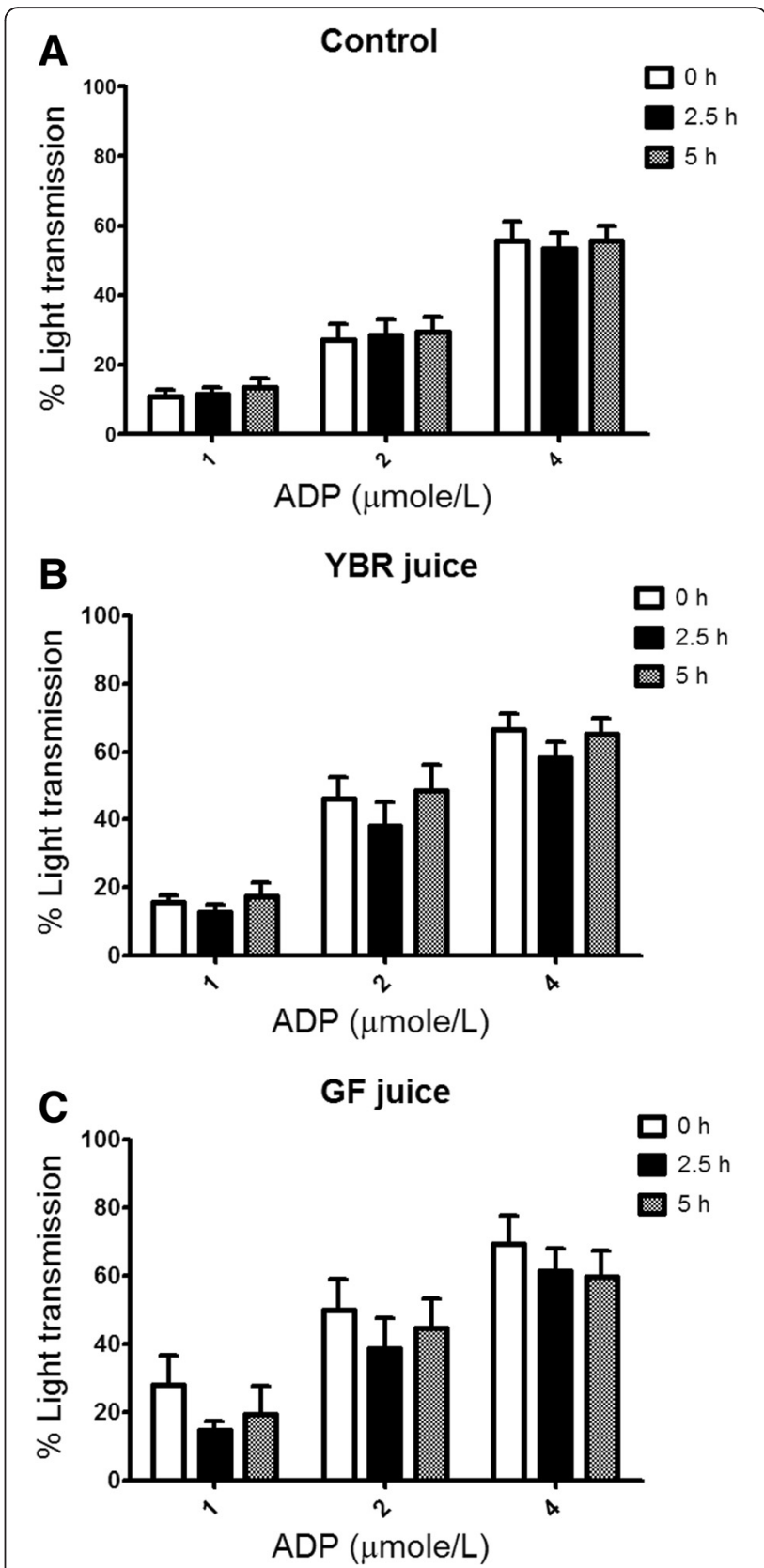

Fig. 3 Effects of the juice ingestion on ex vivo ADP-induced platelet aggregation. Legend: Ex vivo ADP-induced platelet aggregation after the ingestion of water (a), YBR juice (b), or GF juice (c). Data are expressed as mean \pm SEM from 10 subjects in each group. ${ }^{a} P<0.05$ Dunnett's posttest compared to the baseline

\section{Discussion}

Following the ingestion of YBR juice but not GF juice, systemic nitrate concentrations increased rapidly (within $30 \mathrm{~min}$, peaking at $1.5 \mathrm{~h}$ ). Our results were in accordance with previous studies which showed that dietary nitrate was readily absorbed from the stomach and proximal intestine into the blood [13, 14]. Systemic nitrite concentrations, however, increased slowly (within $1.5 \mathrm{~h}$ ), 


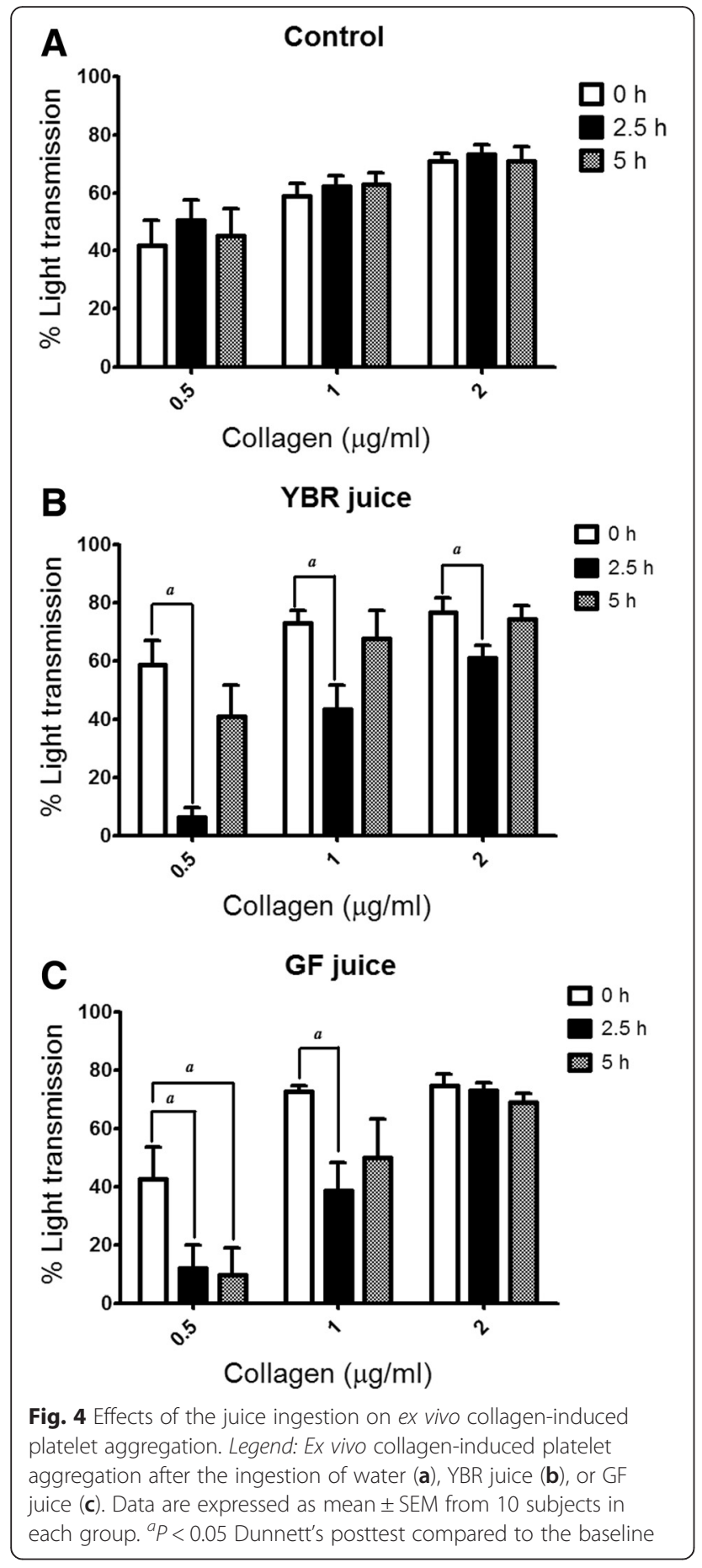

peaked at $2.5-3 \mathrm{~h}$ and returned to the baseline value at $5 \mathrm{~h}$. Since ingested YBR juice contains substantial amount of nitrate with undetectable quantity of nitrite, it was unlikely that systemic nitrite originated from absorbed dietary nitrite. In addition, following the ingestion of YBR juice, levels of plasma nitrite were elevated later than those of plasma nitrate $(1.5 \mathrm{~h}$ vs. $30 \mathrm{~min})$, reflecting the bioconversion of nitrate to nitrite in the

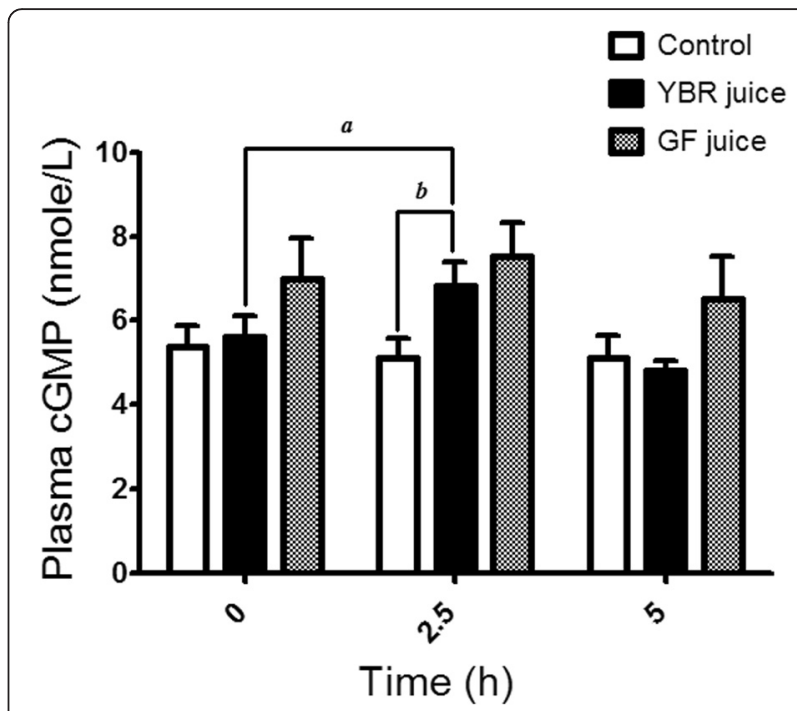

Fig. 5 Effects of the juice ingestion on plasma cGMP concentrations. Legend: Plasma cGMP concentrations at three time points - baseline, 2.5 and $5 \mathrm{~h}$ after the ingestion of water, YBR juice, or GF juice. Data are expressed as mean \pm SEM from 10 subjects in each group. ${ }^{a} P<0.05$ Dunnett's posttest compared to the baseline, ${ }^{b} P<0.05$ Bonferroni posttest vs. the control

body. Our observation was consistent with studies using inorganic nitrate and dietary nitrate (beet root juice) [13, 14]. Previous studies showed that systemic nitrite can be derived from the reduction of nitrate, originated either from NO or diet, to nitrite by two routes. Firstly, nitrate can be reduced to nitrite by commensal facultative anaerobic bacteria present in the oral cavity (i.e. mouth) and possibly in the gastrointestinal tract [36-38]. In a recent cross-over designed study with seven healthy human volunteers, rinsing the mouth with an antibacterial mouth wash has been shown to abolish conversion of nitrate to nitrite in the saliva, and markedly reduce increase in plasma nitrite following a dietary nitrate load

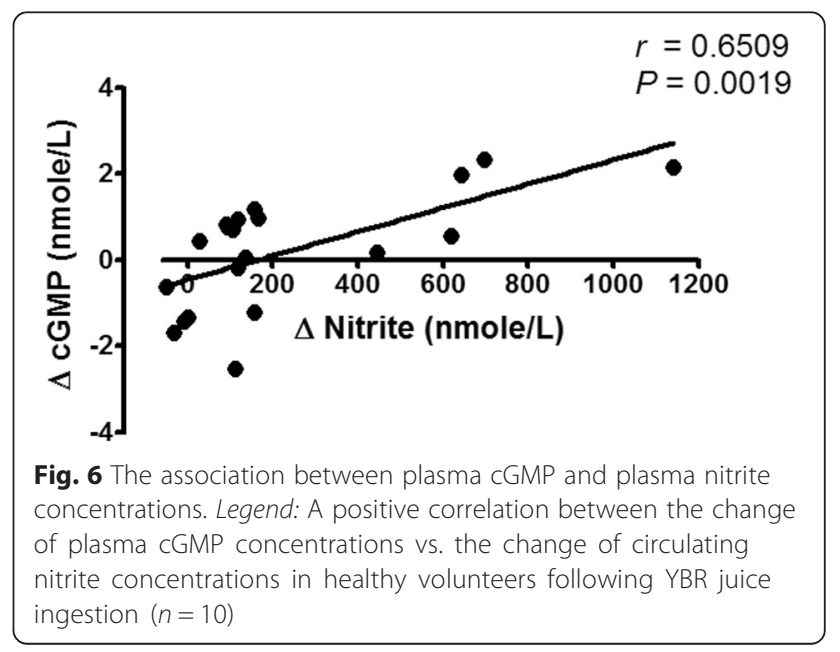




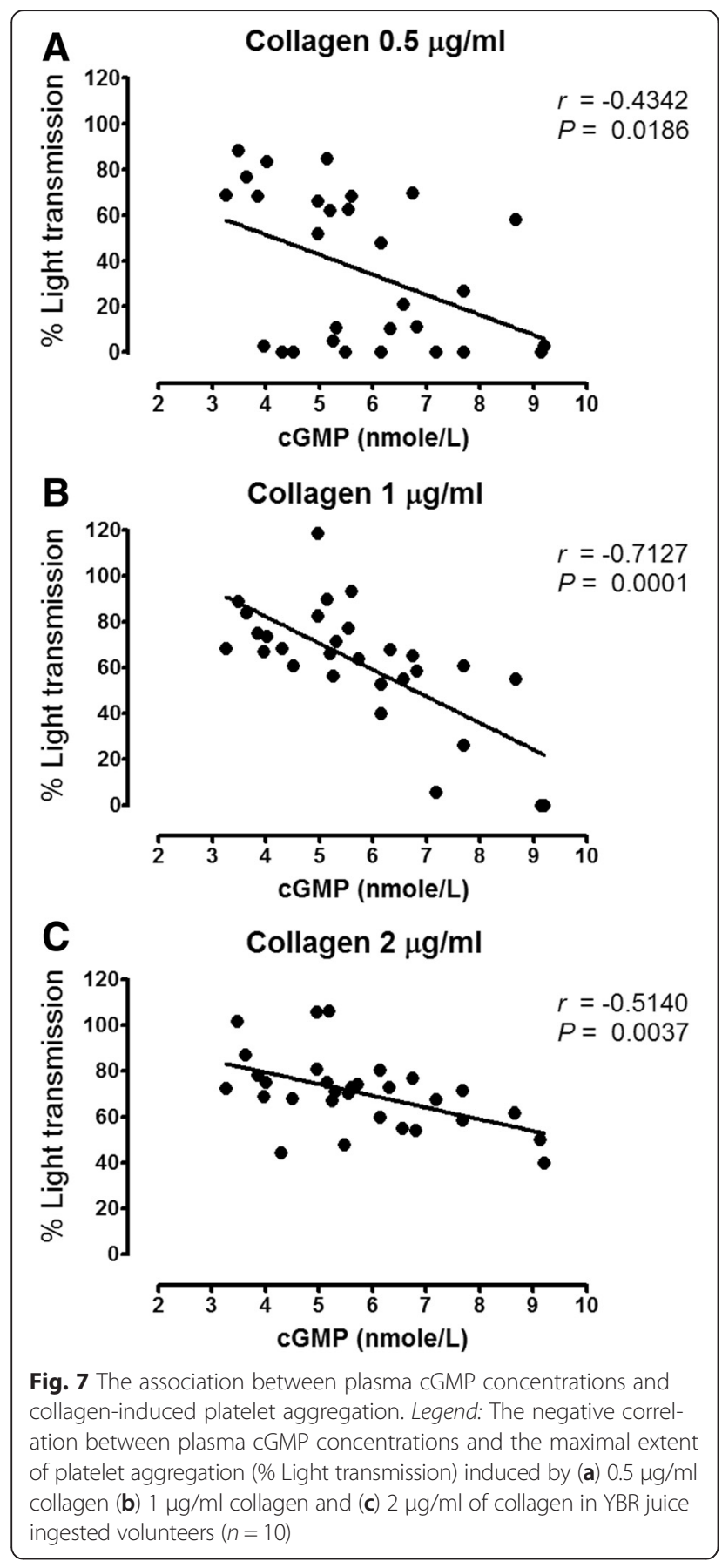

[38]. It is thus suggested that oral bacteria play a crucial role in the reduction of nitrate to nitrite and contribute to systemic nitrite levels. Secondly, the other possibility for systemic nitrate reduction to nitrite is nitrate reductase enzymes present in tissues such as lung, liver, heart, and kidney [39]. It was demonstrated that mammalian tissues reduce inorganic nitrate to nitrite and this effect was significantly inhibited by allopurinol, suggesting that molybdenum-based oxidoreductase enzymes, such as xanthine oxidase, present in mammalian tissues may catalyze, at least in part, the reduction of nitrate to nitrite and contribute to systemic nitrite levels. In harmony with previous studies, the present study suggested that following the ingestion of YBR juice the nitrate content in YBR juice was absorbed and was further converted to nitrite in the body.

In this study, we have shown that both YBR and GF juices attenuated ex vivo collagen-induced platelet aggregation. However, only the inhibition by YBR juice at $2.5 \mathrm{~h}$ after the ingestion was concurrent with the peaking of systemic nitrite concentrations. Moreover, at $5 \mathrm{~h}$ after YBR juice ingestion, both systemic nitrite concentrations and collagen-induced platelet aggregation were simultaneously returned to baseline values. Supplementation with $2 \mathrm{mmole} / \mathrm{L}$ potassium nitrate has been demonstrated to inhibit platelet aggregation [40]. Dietary supplement with nitrate (beetroot juice) has been shown to inhibit ex vivo platelet aggregation in healthy volunteers [14]. Moreover, nitrite was shown to inhibit platelet aggregation in a cat model [41]. Our results suggest that systemic nitrite derived from dietary nitrate in YBR juice may involve in the mechanism of platelet inhibition.

Recently, Sihirun et al. [42] showed that nitrite itself did not directly inhibit platelet aggregation in vitro and suggested that nitrite might be further converted to NO which attenuated platelet aggregation. Cosby et al. [43] demonstrated increased NO formation in the blood, as measured by the rate of formation of ironnitrosylated hemoglobin $(\mathrm{HbNO})$ during nitrite infusion at rest and under exercise, suggesting that nitrite represents a major bioavailable pool of NO. Recently, it was shown that inorganic nitrate ingestion in males elevated platelet cGMP levels, implicating a role of $\mathrm{NO}$ in the antiaggregating effect of nitrate in vivo [44]. Accordingly, we demonstrated that following YBR juice ingestion, similar concentration-time profiles of systemic nitrite and plasma cGMP were apparent. In addition, a positive correlation $(r=0.6509, P<0.05)$ between the extent of increases in plasma nitrite from the baseline and the extent of increases in plasma cGMP from the baseline was evident. Nitrate was previously shown to increase the plasma cGMP [45]. Arteriolar cGMP production has been used to assess the activation of soluble guanylyl cyclase in vivo [45]. Many investigators adopted nitrate and plasma cGMP measurements as a reliable indicator of NO amplification during physiological [4, 7] and pharmacological stimulations $[5,8]$. Moreover, a previous study showed that collagen-induced platelet adhesion and aggregation were inhibited by NO donor $S$-nitrosoglutathione (GSNO) [46]. Our results also showed the negative correlation between plasma cGMP concentrations and the maximal extent of ex vivo platelet aggregation induced by varying concentrations of collagen $(0.5-2 \mu \mathrm{g} / \mathrm{ml})$ in YBR juice group. During 
Table 2 Time courses of SBP, DBP and HR values before and after YBR, GF, or water ingestion

\begin{tabular}{|c|c|c|c|c|c|c|c|c|c|}
\hline \multirow{2}{*}{$\begin{array}{l}\text { Time } \\
\text { (h) }\end{array}$} & \multicolumn{3}{|c|}{$\mathrm{SBP}(\mathrm{mmHg})$} & \multicolumn{3}{|c|}{$\mathrm{DBP}(\mathrm{mmHg})$} & \multicolumn{3}{|c|}{ HR (beats/min) } \\
\hline & Control & YBR & GF & Control & YBR & GF & Control & YBR & GF \\
\hline \multirow[t]{2}{*}{0} & 103.10 & 111.90 & 116.20 & 69.30 & 72.00 & 73.22 & 76.70 & 74.10 & 77.11 \\
\hline & \pm 3.38 & \pm 3.25 & \pm 2.71 & \pm 2.82 & \pm 2.46 & \pm 1.95 & \pm 3.07 & \pm 3.64 & \pm 3.36 \\
\hline \multirow[t]{2}{*}{0.5} & 108.50 & 112.90 & 114.10 & 70.90 & $64.70^{a, b}$ & 68.44 & 75.30 & 69.80 & 72.44 \\
\hline & \pm 3.58 & \pm 2.98 & \pm 3.25 & \pm 2.86 & \pm 4.15 & \pm 2.29 & \pm 2.77 & \pm 4.55 & \pm 1.58 \\
\hline \multirow[t]{2}{*}{1} & 106.40 & 110.70 & 113.50 & 69.10 & 68.70 & 68.00 & 77.50 & 74.60 & 76.78 \\
\hline & \pm 2.84 & \pm 2.98 & \pm 2.64 & \pm 2.24 & \pm 1.89 & \pm 1.61 & \pm 3.60 & \pm 4.99 & \pm 3.53 \\
\hline \multirow[t]{2}{*}{1.5} & 106.50 & 106.60 & 111.40 & 70.30 & 67.70 & 71.11 & 77.00 & 73.90 & 75.11 \\
\hline & \pm 2.81 & \pm 3.20 & \pm 2.07 & \pm 3.09 & \pm 2.65 & \pm 3.14 & \pm 3.43 & \pm 4.10 & \pm 1.52 \\
\hline \multirow[t]{2}{*}{2} & 102.80 & 109.00 & 107.10 & 68.10 & 67.00 & $65.56^{a}$ & 75.70 & 72.20 & 74.33 \\
\hline & \pm 3.61 & \pm 3.62 & \pm 3.04 & \pm 2.84 & \pm 1.61 & \pm 2.50 & \pm 2.89 & \pm 4.04 & \pm 2.43 \\
\hline \multirow[t]{2}{*}{2.5} & 105.50 & 106.50 & $110.10^{a}$ & 71.00 & 66.30 & 67.67 & 73.80 & 69.80 & $71.56^{a}$ \\
\hline & \pm 2.24 & \pm 3.13 & \pm 3.21 & \pm 2.69 & \pm 2.51 & \pm 1.77 & \pm 2.69 & \pm 3.94 & \pm 2.65 \\
\hline \multirow[t]{2}{*}{3} & 101.20 & 105.70 & 111.50 & 65.90 & 67.50 & $65.33^{a}$ & 73.80 & 70.90 & $72.11^{a}$ \\
\hline & \pm 1.65 & \pm 2.28 & \pm 2.13 & \pm 1.88 & \pm 3.08 & \pm 1.43 & \pm 3.50 & \pm 4.04 & \pm 2.17 \\
\hline \multirow[t]{2}{*}{5} & 106.50 & 106.60 & $108.50^{a, b}$ & 70.00 & 69.30 & 68.67 & 74.80 & 69.70 & $69.78^{a}$ \\
\hline & \pm 2.32 & \pm 1.99 & \pm 2.77 & \pm 2.54 & \pm 2.13 & \pm 1.41 & \pm 3.99 & \pm 4.07 & \pm 2.15 \\
\hline
\end{tabular}

Data are expressed as mean \pm SEM from 10 subjects in each group. ${ }^{a} P<0.05$ Dunnett's posttest compared to the baseline, ${ }^{b} P<0.05$ Bonferroni posttest vs. the control

inhalation of NO, increased plasma cGMP concentrations and inhibition of platelet aggregation have been previously reported [47, 48]. Therefore, results of the present study in conjunction with previous studies suggested that following YBR ingestion, systemic nitrite that converted from systemic nitrate was further converted to $\mathrm{NO}$ which attenuated platelet responses to collagen stimulation. On the contrary, our results demonstrated that YBR juice intake did not inhibit ADP-induced platelet aggregation.

The ingestion of GF juice also attenuated collageninduced but not ADP-induced platelet aggregation.

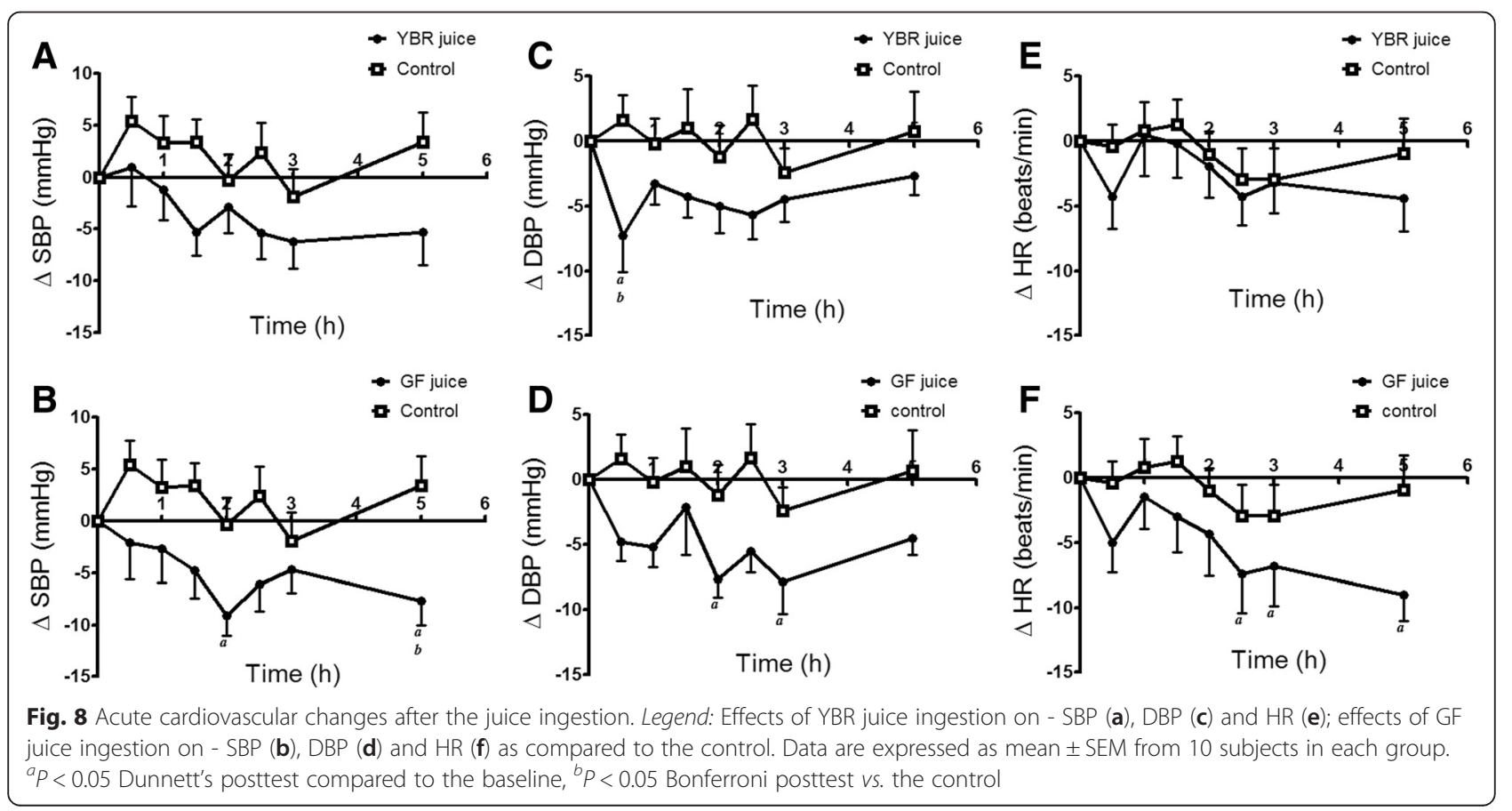


However, our results showed that the inhibition of collagen-induced platelet aggregation by GF was not associated with systemic nitrate and nitrite concentrations. Guava is a flavonoid-rich fruit $[49,50]$, and flavonoid compounds existed in guava fruit were reported including myricetin, apigenin, leucocyanidin, quercetin, quercetin-3- $\alpha-\mathrm{L}$ arabinofuranoside, quercetin $3-\beta-\mathrm{D}$ glucoside, quercertin $3-\beta$-galactoside, and quercitrin [ 50 , 51]. Hubbard and coworkers [52] proposed that the ingestion of quercetin-4-o- $\beta$-d-glucoside inhibited collageninduced platelet aggregation via the reduction in phosphorylation of tyrosine kinase Syk and phospholipase C 2 , which are signaling components of the platelet glycoprotein VI collagen receptor. In addition, some studies suggested possible mechanisms by which flavonoids exert their antiplatelet property; lowering intracellular $\mathrm{Ca}^{2+}$ levels, alteration in the metabolism of cAMP and thromboxane $\mathrm{A}_{2}[53,54]$. It is likely that flavonoids in GF juice might be responsible for the platelet inhibitory action, a speculation that requires further investigations.

Webb and coworkers [14] demonstrated that the ingestion of nitrate load (beetroot juice) reduced both systolic and diastolic blood pressure in healthy human volunteers, an effect that correlated with the peak increase in plasma nitrite concentrations. Our study showed that YBR juice reduced DBP only at $0.5 \mathrm{~h}$ after the ingestion and this response showed no association with both nitrate and nitrite concentrations. Lacking of cardiovascular effects of YBR juice may be due to relatively low systemic concentrations of both nitrate and nitrite after YBR ingestion as compared to those of beet root juice. Peak concentrations of systemic nitrate and nitrite after YBR juice ingestion were $150 \mu$ mole/L and $0.4 \mu \mathrm{mole} / \mathrm{L}$, respectively, and those after beetroot juice ingestion were $400 \mu \mathrm{mole} / \mathrm{L}$ for systemic nitrate and 0.6 $\mu$ mole/L for systemic nitrite. In general, it is rather difficult to see changes of cardiovascular responses induced by low concentrations of these substances in healthy volunteers. However, these variables may be altered by emotional changes, the position of subjects, as well as pathological conditions. Our results showed that GF juice ingestion affected all cardiovascular variables measured. The effect of GF juice on SBP in the present study is supported by a previous study which showed the antihypertensive effect of pink guava puree in spontaneous hypertensive rats [25]. Vasodilator and antioxidant actions exerted by the guava extract have also been reported [24]. In patients with essential hypertension, guava extracts supplemented for twelve weeks significantly decreased SBP with a significant increase in HDL [55]. Our results also demonstrated the cardiac depressive effect of GF juice intake. Similarly, guava leaf extract was previously demonstrated to have cardiac depressant activities in the cardiac tissue [27] and animal model
[56]. Overall, the apparent limitation of our study is using a relatively small number of subjects per group which might lead to the arbitrary generalization of study outcome.

\section{Conclusion}

The present study showed, for the first time, the acute platelet inhibitory effect of YBR juice and GF juice ingestion in healthy volunteers. YBR juice contained a substantial amount of dietary nitrate which, following ingestion, was absorbed and further converted to nitrite in the body. Systemic nitrite might be further converted to NO which attenuated platelet responses to collagen stimulation following YBR juice ingestion. In addition, the ingestion of YBR juice reduced only DBP while the ingestion of GF juice reduced SBP, DBP and HR. As our concern on primary prevention, the consumption of YBR and GF juices might promote public cardiovascular health through their roles in platelet inhibition and blood pressure lowering. Further works are needed to fully elucidate the molecular mechanism of actions of YBR and GF juices in several physiological processes in order to prove their prophylactic and therapeutic potentials.

\begin{abstract}
Abbreviations
cGMP, cyclic guanosine monophosphate; DBP, diastolic blood pressure; GF, guava fruit; HR, heart rate; NO, nitric oxide; SBP, systolic blood pressure; YBR, yam bean root
\end{abstract}

\section{Acknowledgements}

We thank all subjects for participating in this study. We also thank Dr. Surachai Unchern for editing the manuscript.

\section{Funding}

This study was supported by a grant from the Thailand Research Fund (TRF).

\section{Availability of data and materials}

The datasets and materials supporting the conclusions of this article are presented in this main paper.

\section{Authors' contributions}

SU research design; NS provision of analytical tools; TT and TK conducting research; Supeenun Unchern and Thitiporn Thaptimthong - data analysis and writing the manuscript. All authors read and approved the final manuscript.

\section{Competing interests}

The authors declare that they have no competing interests.

\section{Consent for publication}

Not applicable.

\section{Ethics approval and consent of participate}

Ethical approval was received from the Clinical Research Ethics Committee of Ramathibodi Hospital, Mahidol University (protocol number: ID 03-54-25). All participants provided informed written consent.

Received: 8 February 2015 Accepted: 13 June 2016

Published online: 03 August 2016

\section{References}

1. Naseem KM. The role of nitric oxide in cardiovascular diseases. Mol Aspects Med. 2005;26:33-65. 
2. Giansante C, Fiotti N. Insights into human hypertension: the role of endothelial dysfunction. J Hum Hypertens. 2006;20(10):725-6.

3. Kwon O, Hong SM, Ramesh G. Diminished NO generation by injured endothelium and loss of macula densa nNOS may contribute to sustained acute kidney injury after ischemia-reperfusion. Am J Physiol Renal Physiol. 2009;296(1):F25-33.

4. Zhao HJ, Wang S, Cheng H, Zhang MZ, Takahashi T, Fogo AB, et al. Endothelial nitric oxide synthase deficiency produces accelerated nephropathy in diabetic mice. J Am Soc Nephrol. 2006;17(10):2664-9.

5. Ohara Y, Peterson TE, Harrison DG. Hypercholesterolemia increases endothelial superoxide anion production. J Clin Invest. 1993;91(6):2546-51.

6. Quyyumi AA, Dakak N, Andrews NP, Husain S, Arora S, Gilligan DM, et al. Nitric oxide activity in the human coronary circulation. Impact of risk factors for coronary atherosclerosis. J Clin Invest. 1995;95(4):1747-55.

7. Zand J, Lanza F, Garg HK, Bryan NS. All-natural nitrite and nitrate containing dietary supplement promotes nitric oxide production and reduces triglycerides in humans. Nutr Res. 2011;31(4):262-9.

8. Ito K, Chen J, Seshan SV, Khodadadian JJ, Gallagher R, El Chaar M, et al. Dietary arginine supplementation attenuates renal damage after relief of unilateral ureteral obstruction in rats. Kidney Int. 2005;68(2):515-28.

9. Appel LJ, Moore TJ, Obarzanek E, Vollmer WM, Svetkey LP, Sacks FM, et al. A clinical trial of the effects of dietary patterns on blood pressure. DASH Collaborative Research Group. N Engl J Med. 1997;336(16):1117-24.

10. Bryan NS, Calvert JW, Elrod JW, Gundewar S, Ji SY, Lefer DJ. Dietary nitrite supplementation protects against myocardial ischemia-reperfusion injury. Proc Natl Acad Sci U S A. 2007;104(48):19144-9.

11. Sobko T, Marcus C, Govoni M, Kamiya S. Dietary nitrate in Japanese traditional foods lowers diastolic blood pressure in healthy volunteers. Nitric Oxide. 2010;22(2):136-40.

12. Lidder S, Webb AJ. Vascular effects of dietary nitrate (as found in green leafy vegetables and beetroot) via the nitrate-nitrite-nitric oxide pathway. $\mathrm{Br} J$ Clin Pharmacol. 2013;75(3):677-96.

13. Kapil V, Milsom AB, Okorie M, Maleki-Toyserkani S, Akram F, Rehman F, et al. Inorganic nitrate supplementation lowers blood pressure in humans: role for nitrite-derived NO. Hypertension. 2010;56(2):274-81.

14. Webb AJ, Patel N, Loukogeorgakis S, Okorie M, Aboud Z, Misra S, et al. Acute blood pressure lowering, vasoprotective, and antiplatelet properties of dietary nitrate via bioconversion to nitrite. Hypertension. 2008;51(3):784-90

15. Freedman JE, Parker 3rd C, Li L, Perlman JA, Frei B, Ivanov V, et al. Select flavonoids and whole juice from purple grapes inhibit platelet function and enhance nitric oxide release. Circulation. 2001;103(23):2792-8.

16. Mattiello T, Trifiro E, Jotti GS, Pulcinelli FM. Effects of pomegranate juice and extract polyphenols on platelet function. J Med Food. 2009;12(2):334-9.

17. George TW, Niwat C, Waroonphan S, Gordon MH, Lovegrove JA. Effects of chronic and acute consumption of fruit- and vegetable-puree-based drinks on vasodilation, risk factors for CVD and the response as a result of the eNOS G298T polymorphism. Proc Nutr Soc. 2009;68(2):148-61.

18. Ekshyyan VP, Hebert VY, Khandelwal A, Dugas TR. Resveratrol inhibits rat aortic vascular smooth muscle cell proliferation via estrogen receptor dependent nitric oxide production. J Cardiovasc Pharmacol. 2007;50(1):83-93.

19. de Nigris F, Williams-Ignarro S, Lerman LO, Crimi E, Botti C, Mansueto G, et al. Beneficial effects of pomegranate juice on oxidation-sensitive genes and endothelial nitric oxide synthase activity at sites of perturbed shear stress. Proc Natl Acad Sci U S A. 2005;102(13):4896-901.

20. Morand C, Dubray C, Milenkovic D, Lioger D, Martin JF, Scalbert A, et al. Hesperidin contributes to the vascular protective effects of orange juice: a randomized crossover study in healthy volunteers. Am J Clin Nutr. 2011; 93(1):73-80

21. Morand C, Milenkovic D, Chanet A, Deval C, Mazur A. Nutrigenomic effects of hesperidin, the major polyphenol of orange, related to its cardiovascular protective effects. FASEB J. 2011;25:582-9.

22. Reshef N, Hayari Y, Goren C, Boaz M, Madar Z, Knobler H. Antihypertensive effect of sweetie fruit in patients with stage I hypertension. Am J Hypertens. 2005;18(10):1360-3.

23. Geidam Y, Ambali A, Onyeyili P. Phytochemical Screening and Antibacterial Properties of Organic Solvent Fractions of Psidium guajava Aqueous Leaf Extracts. Int J Pharmacol. 2007;3:68-73.

24. Jiménez-Escrig A, Rincón M, Pulido R, Saura-Calixto F. Guava fruit (Psidium guajava L.) as a new source of antioxidant dietary fiber. J Agric Food Chem. 2001:49(11):5489-93.
25. Ayub M, Norazmir M, Mamot S, Jeeven K, Hadijah H. Anti-hypertensive effect of pink guava Psidium guajava puree on spontaneous hypertensive rats. Inter Food Res J. 2010;17:89-96.

26. Yamashiro S, Noguchi K, Matsuzaki T, Miyagi K, Nakasone J, Sakanashi $M$, et al. Cardioprotective effects of extracts from Psidium guajava $L$ and Limonium wrightii, Okinawan medicinal plants, against ischemiareperfusion injury in perfused rat hearts. Pharmacology. 2003;67(3): 128-35.

27. Gondim A, de Oliveira V, dos Santos S, da Silva B, de Vasconcelos C, Conde-Garcia E. Exract from leaf of Psidium guajava $\mathrm{L}$. depresses the guinea pig atrial contractility by interfering with potassium and calcium channels. Braz J Pharm Sci. 2010;43(5):483-9.

28. Kumalasari ID, Nishi K, Harmayani E, Raharjo S, Sugahara T. Immunomodulatory activity of Bengkoang (Pachyrhizus erosus) fiber extract in vitro and in vivo. Cytotechnology. 2014;66(1):75-85.

29. Yang BK, Vivas EX, Reiter CD, Gladwin MT. Methodologies for the sensitive and specific measurement of S-nitrosothiols, iron-nitrosyls, and nitrite in biological samples. Free Radic Res. 2003;37(1):1-10.

30. Pelletier MM, Kleinbongard P, Ringwood L, Hito R, Hunter CJ, Schechter AN et al. The measurement of blood and plasma nitrite by chemiluminescence: pitfalls and solutions. Free Radic Biol Med. 2006;41(4):541-8.

31. Basu S, Wang X, Gladwin MT, Kim-Shapiro DB. Chemiluminescent detection of S-nitrosated proteins: comparison of tri-iodide, copper/CO/ cysteine, and modified copper/cysteine methods. Methods Enzymol. 2008:440:137-56.

32. Born GVR, Cross MJ. The aggregation of blood platelets. J Physiol. 1963;168:178-95.

33. Jarvis GE. Platelet aggregation: turbidimetric measurements. Methods Mol Biol. 2004;272:65-76.

34. Fogh-Andersen N, Wimberley PD, Thode J, Siggaard-Andersen O. Determination of sodium and potassium with ion-selective electrodes. Clin Chem. 1984;30(3):433-6.

35. Preik-Steinhoff $H$, Kelm M. Determination of nitrite in human blood by combination of a specific sample preparation with high-performance anionexchange chromatography and electrochemical detection. J Chromatogr B Biomed Appl. 1996;685(2):348-52.

36. Dougall HT, Smith L, Duncan C, Benjamin N. The effect of amoxycillin on salivary nitrite concentrations: an important mechanism of adverse reactions? Br J Clin Pharmacol. 1995;39(4):460-2.

37. Duncan $C$, Dougall $H$, Johnston $P$, Green $S$, Brogan $R$, Leifert $C$, et al. Chemical generation of nitric oxide in the mouth from the enterosalivary circulation of dietary nitrate. Nat Med. 1995;1 (6):546-51.

38. Govoni M, Jansson EA, Weitzberg E, Lundberg JO. The increase in plasma nitrite after a dietary nitrate load is markedly attenuated by an antibacterial mouthwash. Nitric Oxide. 2008:19(4):333-7.

39. Jansson EA, Huang L, Malkey R, Govoni M, Nihlen C, Olsson A, et al. A mammalian functional nitrate reductase that regulates nitrite and nitric oxide homeostasis. Nat Chem Biol. 2008;4(7):411-7.

40. Richardson G, Hicks SL, O'Byrne S, Frost MT, Moore K, Benjamin N, et al. The ingestion of inorganic nitrate increases gastric S-nitrosothiol levels and inhibits platelet function in humans. Nitric Oxide. 2002;7(1):24-9.

41. Johnson 3rd G, Tsao PS, Mulloy D, Lefer AM. Cardioprotective effects of acidified sodium nitrite in myocardial ischemia with reperfusion. J Pharmacol Exp Ther. 1990;252(1):35-41.

42. Srihirun S, Sriwantana T, Unchern S, Kittikool D, Noulsri E, Pattanapanyasat K, et al. Platelet inhibition by nitrite is dependent on erythrocytes and deoxygenation. PLoS One. 2012;7(1):e30380.

43. Cosby K, Partovi KS, Crawford JH, Patel RP, Reiter CD, Martyr S, et al. Nitrite reduction to nitric oxide by deoxyhemoglobin vasodilates the human circulation. Nat Med. 2003;9(12):1498-505.

44. Velmurugan S, Kapil V, Ghosh SM, Davies S, McKnight A, Aboud Z, et al. Antiplatelet effects of dietary nitrate in healthy volunteers: involvement of cGMP and influence of sex. Free Radic Biol Med. 2013;65:1521-32.

45. Tsutamoto T, Kinoshita M, Ohbayashi Y, Wada A, Maeda Y, Adachi T. Plasma arteriovenous CGMP difference as a useful indicator of nitrate tolerance in patients with heart failure. Circulation. 1994;90(2):823-9.

46. Roberts W, Riba R, Homer-Vanniasinkam S, Farndale RW, Naseem KM. Nitric oxide specifically inhibits integrin-mediated platelet adhesion and spreading on collagen. J Thromb Haemost. 2008;6(12):2175-85.

47. Beghetti M, Sparling C, Cox PN, Stephens D, Adatia I. Inhaled NO inhibits platelet aggregation and elevates plasma but not intraplatelet CGMP in 
healthy human volunteers. Am J Physiol Heart Circ Physiol. 2003;285(2): H637-42.

48. Gries A, Bode C, Peter K, Herr A, Bohrer H, Motsch J, et al. Inhaled nitric oxide inhibits human platelet aggregation, P-selectin expression, and fibrinogen binding in vitro and in vivo. Circulation. 1998;97(15):1481-7.

49. Mhatre M, Tilak-Jain J, De S, Devasagayam TP. Evaluation of the antioxidant activity of non-transformed and transformed pineapple: a comparative study. Food Chem Toxicol. 2009;47(11):2696-702.

50. Miean KH, Mohamed S. Flavonoid (myricetin, quercetin, kaempferol, luteolin, and apigenin) content of edible tropical plants. J Agric Food Chem. 2001; 49(6):3106-12

51. Gutierrez RM, Mitchell S, Solis RV. Psidium guajava: a review of its traditional uses, phytochemistry and pharmacology. J Ethnopharmacol. 2008;117(1):1-27.

52. Hubbard GP, Wolffram S, Lovegrove JA, Gibbins JM. Ingestion of quercetin inhibits platelet aggregation and essential components of the collagenstimulated platelet activation pathway in humans. J Thromb Haemost. 2004; 2(12):2138-45.

53. Dutta-Roy AK, Gordon MJ, Kelly C, Hunter K, Crosbie L, Knight-Carpentar T, et al. Inhibitory effect of Ginkgo biloba extract on human platelet aggregation. Platelets. 1999;10(5):298-305.

54. Kang W, Chung K, Chung J, Lee J, Park J, Zhang Y, et al. Antiplatelet activity of green tea catechins is mediated by inhibition of cytoplasmic calcium increase. J Cardiovasc Pharmacol. 2001;38(6):875-84.

55. Singh RB, Rastogi SS, Singh R, Ghosh S, Niaz MA. Effects of guava intake on serum total and high-density lipoprotein cholesterol levels and on systemic blood pressure. Am J Cardiol. 1992;70(15):1287-91.

56. Ojewole JA. Hypoglycemic and hypotensive effects of Psidium guajava Linn. (Myrtaceae) leaf aqueous extract. Methods Find Exp Clin Pharmacol. 2005; 27(10):689-95.

\section{Submit your next manuscript to BioMed Central and we will help you at every step:}

- We accept pre-submission inquiries

- Our selector tool helps you to find the most relevant journal

- We provide round the clock customer support

- Convenient online submission

- Thorough peer review

- Inclusion in PubMed and all major indexing services

- Maximum visibility for your research

Submit your manuscript at www.biomedcentral.com/submit 